\title{
Comparative study on thermal cracking characteristics and bio-oil production from different microalgae using Py-GC/MS
}

\author{
Gang $\mathrm{Li}^{1}$, Fang $\mathrm{Ji}^{2}$, Xue Bai ${ }^{1}$, Yuguang Zhou ${ }^{3,4,5}$, Renjie Dong ${ }^{4,5,6}$, Zhigang Huang ${ }^{1 *}$ \\ (1. College of Materials and Mechanical Engineering, Beijing Technology and Business University, Beijing 100048, China; \\ 2. Chinese Academy of Agricultural Engineering Planning and Design, Beijing 100125, China; \\ 3. Bioenergy and Environment Science \& Technology Laboratory, College of Engineering, China Agricultural University, \\ Beijing 100083, China; 4. Key Laboratory of Clean Production and Utilization of Renewable Energy, Ministry of Agriculture, \\ China, Beijing 100083, China; 5. National Center for International Research of BioEnergy Science and Technology, \\ Ministry of Science and Technology, Beijing 100083, China; 6. Yantai Institute, China Agricultural University, Yantai 264670, China)
}

\begin{abstract}
The yield and chemical composition of pyrolysis products of Chlorella pyrenoidosa and Schizochytrium limacinum were determined using thermogravimetric analyzer (TGA) and pyrolysis-gas chromatographic mass spectrometry (Py-GC/MS) by varying the temperature ranges. After further analysis of the total ion current (TIC) diagrams of Chlorella pyrenoidosa and Schizochytrium limacinum, it was concluded that both the pyrolysis products of each sample were mainly comprised of hydrocarbons, aromatics, fatty acids, nitrogen compounds, PAHs, phenols, etc, however, the relative content of each compound from Chlorella pyrenoidosa and Schizochytrium limacinum was different. The pyrolysis of Chlorella pyrenoidosa and Schizochytrium limacinum at $350^{\circ} \mathrm{C}$ produced a maximum yield of bio-oil production $(44.32 \%$ and $60.99 \%)$; moreover, Chlorella pyrenoidosa could lead to more pollutants (nitrogen compounds and PAHs) release (2.71\%) compared to that of Schizochytrium limacinum $(0.7 \%)$. Considering the reasonable bio-oil production and minimum release of pollutants, Schizochytrium limacinum was found to be superior for producing biofuel against Chlorella pyrenoidosa.
\end{abstract}

Keywords: microalgae, Chlorella pyrenoidosa, Schizochytrium limacinum, bio-oil production, thermal cracking, Py-GC-MS DOI: $10.25165 /$ j.ijabe.20191201.3628

Citation: Li G, Ji F, Bai X, Zhou Y G, Dong R J, Huang Z G. Comparative study on thermal cracking characteristics and bio-oil production from different microalgae using Py-GC/MS. Int J Agric \& Biol Eng, 2019; 12(1): 208-213.

\section{Introduction}

The pollution caused by hazardous substances that emitted from the massive use of fossil energy is serious increasingly so as to create global ecological problems such as greenhouse effect, climate change, destruction for diversity of species and desertification. It has been paid increasing attention on searching for renewable and alternative energy sources ${ }^{[1]}$. Among all the proposed alternatives, biomass for bioenergy production is considered as a sustainable, renewable and geographically evenly distributed resource ${ }^{[2]}$. Microalgae, as one of the major feedstocks for the third-generation biofuel production, have been attractive due to their advantages such as high photosynthesis efficiency, short growth period and high oil content as well as the advantage that the production with high density and large scale can be

\section{Received date: 2017-10-31 Accepted date: 2018-12-27}

Biographies: Gang Li, $\mathrm{PhD}$, Associate Professor, research interests: microalgae conversion and bioenergy, agricultural product processing engineering, Email: ligang@btbu.edu.cn; Fang Ji, PhD, Engineer, research interest: biomass engineering, Email: ji_fang1984@163.com; Xue Bai, Master, research interest: agricultural product processing engineering, Email: 1510233569@qq.com; Yuguang Zhou, PhD, Associate Professor, research interest: bioenergy clean utilization, Email: zhouyg@cau.edu.cn; Renjie Dong, Professor, research interest: bioenergy clean utilization, Email: rjdong@cau.edu.cn .

*Corresponding author: Zhigang Huang, Professor, research interest: agricultural product processing engineering. College of Material and Mechanical Engineering, Beijing Technology and Business University, No. 11 Fucheng Road, Haidian District, Beijing 100048, China. Tel/Fax: +86-10-68985249, Email: huangzg@btbu.edu.cn. accomplished $^{[3-5]}$.

At present, it is still not fully understood for the mechanisms of generation as well as modification of products for the microalgae biomass via pyrolysis. The major compounds in microalgae involve oil, protein, soluble polysaccharides, and so on ${ }^{[6]}$. Research has shown that the ecological situation during cultivation of microalgae pose effects on the concentration process of any dominated element involved ${ }^{[7]}$. Therefore, the study on pyrolysis of Chlorella pyrenoidosa and Schizochytrium limacinum is of great significance to detect the basic principles behind the first and the second-order pyrolysis processes, and their application.

Generally, thermochemical conversion of biomass consists of direct combustion, liquefaction, gasification, and pyrolysis ${ }^{[8]}$. As a promising thermochemical conversion, it is well-known that fast pyrolysis can convert biomass directly into solid, liquid, and gaseous products by thermal decomposition of biomass in an oxygen-free atmosphere ${ }^{[3]}$. Pyrolyzer-gas chromatography-mass spectrometer (Py-GC-MS) is one of the most effective ways for complicated compound analysis. Separation and extraction of substances are required before spectrum methods. After combing with a pyrolyzer, the application of GC-MS has been extended to a wider aspect and can be suitable for more compounds to be analyzed, including the non-volatile solid organic samples. The best effect is to provide better performance of sample injection ${ }^{[9-12]}$.

In most cases, several micrograms of samples can be instantly pyrolyzed at $300^{\circ} \mathrm{C}-800^{\circ} \mathrm{C}$. The series of spectrum of pyrolyzed product can be obtained since its volatility gets weaker along with the increasing in molecular weight. If Py-GC-MS was employed 
in the study of Chlorella pyrenoidosa and Schizochytrium limacinum, the spectrum is expected to provide more abundant information about the bio-oil production and its composition, in addition with the specific differences of bio-oil from each microalgae.

\section{Materials and methods}

\subsection{Sample preparation}

The Chlorella pyrenoidosa and Schizochytrium limacinum samples were purchased from Wudi Bioengineering Co., Ltd. (Shandong, China) and preserved at $4^{\circ} \mathrm{C}$ in sealed plastic bags.

\subsection{Compositional analysis}

The carbon, hydrogen, nitrogen, and sulfur contents in sample were measured using an elemental analyzer (Flash EA-1112, Thermo, USA) at the Institute of Chemistry, Chinese Academy of Sciences. Reported values were from the average of at least triplicate samples. Based on the elemental composition, the high heating values (HHV) of samples were calculated using the well-established correlations ${ }^{[13]}$.

\subsection{Thermogravimetric analysis}

The sample was tested by thermogravimetric analyzer (SDT-Q600, TA Instruments, USA) for the determination of decomposition behavior. Weight calibration of the analyzer was conducted according to the operation manual ${ }^{[14]}$. Approximately 2-4 mg of each sample was measured, put into an alumina oxide pan and loaded into the furnace. Compressed air was purged into the furnace at the rate of $100 \mathrm{~mL} / \mathrm{min}$. The analyzer was programmable controlled and temperature of furnace was ramped from standby temperature $\left(40^{\circ} \mathrm{C}\right)$ to $1000^{\circ} \mathrm{C}$ with an increasing rate of $25^{\circ} \mathrm{C} / \mathrm{min}$.

\subsection{Analytic pyrolysis by Py-GC/MS}

Real-time chemical composition of pyrolysis sample was analyzed using a single-shot pyrolyzer (Frontier Labs 3030i, Japan) connected to a GC-MS (Agilent 7890A/5975C, USA), which was equipped with an inert XL mass spectrum detector and a capillary column (30 m in length, $0.25 \mu \mathrm{m}$ in internal diameter, HP-5 MS, HP19091s-433, Agilent, USA). Concentration level and percentage of different compounds in the pyrolysis products of Chlorella pyrenoidosa and Schizochytrium Limacinum were determined by online $\mathrm{Py}-\mathrm{GC} / \mathrm{MS}$ under a ramping temperature gradient from $350^{\circ} \mathrm{C}$ to $750^{\circ} \mathrm{C}$ at a temperature interval of $100^{\circ} \mathrm{C}$. The analysis condition of GC refers to Table 1 .

Table 1 Analysis condition of GC settings

\begin{tabular}{lc}
\hline \multicolumn{1}{c}{ Name } & Parameters \\
\hline Capillary column & $\mathrm{HP}-5(30 \mathrm{~m} \times 0.25 \mathrm{~mm} \times 0.25 \mu \mathrm{m})$ \\
The carrier gas and flow rate & $\mathrm{He}, 1.0 \mathrm{~mL} / \mathrm{min}$, constant current \\
Inlet temperature & $250^{\circ} \mathrm{C}$ \\
Split ratio & $1: 10$ \\
& Initial temperature $40^{\circ} \mathrm{C}$, keep for $3 \mathrm{~min} ;$ up to \\
Temperature programming & $200^{\circ} \mathrm{C}$ by $5^{\circ} \mathrm{C} / \mathrm{min}$, keep for $5 \mathrm{~min}$; up to $250^{\circ} \mathrm{C}$ \\
& by $10^{\circ} \mathrm{C} / \mathrm{min}$, keep for $5 \mathrm{~min}$. \\
\hline
\end{tabular}

The total ion current (TIC) diagrams of Chlorella pyrenoidosa and Schizochytrium Limacinum pyrolysis products under different temperature conditions were obtained. Results were analyzed using Agilent MSD Productivity Chem Station for GC and GC/MS System Data Analysis application software (Version D 03.00.552, Agilent, USA). Retention time and peak area percentages of different compounds in pyrolysis products were determined by comparing with NIST 2011 Database (Version 2.0, National Institute of Science and Technology, USA). The concentrations of each individual compound were of right proportion to its corresponding peak area percentage.

\section{Results and discussion}

\subsection{Composition analysis}

The results of element analysis and moisture content and higher heating value (HHV) of two kinds of microalgae are shown in Table $2^{[23,24]}$. As a comparison, the results of typical lignocellulosic biomass samples, including sawdust and straw, are also listed ${ }^{[13]}$. Both of the $\mathrm{C}$ and $\mathrm{H}$ contents for Schizochytrium limacinum were higher than Chlorella pyrenoidosa, and especially the $\mathrm{C}$ content was much higher (about 13\%). On the contrary, Chlorella pyrenoidosa showed the highest $\mathrm{N}$ and $\mathrm{S}$ amounts in Table 2. It was reported that higher nitrogen percentage may lead much NOx emissions during combustion ${ }^{[15]}$. Due to the relative high $\mathrm{C}$ and $\mathrm{H}$ content, the HHV of Schizochytrium limacinum was much higher than that of Chlorella pyrenoidosa. Compared with the typical lignocellulosic biomass, the HHV of microalgae was higher, which indicates that microalgae have a great potential in energy production, especially microalgae Schizochytrium limacinum.

Table 2 Compositional analysis of feedstock for pyrolysis

\begin{tabular}{|c|c|c|c|c|c|c|}
\hline \multirow{2}{*}{ Feedstock } & \multicolumn{4}{|c|}{ Elemental analysis $/ \%$} & \multirow{2}{*}{$\begin{array}{c}\text { Moisture } \\
\text { content } \\
\text { (dry basis)/\% }\end{array}$} & \multirow{2}{*}{$\begin{array}{c}\mathrm{HHV} \\
/ \mathrm{MJ}^{\mathrm{kg}} \mathrm{kg}^{-1}\end{array}$} \\
\hline & $\mathrm{C}$ & $\mathrm{H}$ & $\mathrm{N}$ & $\mathrm{S}$ & & \\
\hline Chlorella pyrenoidosa & 46.025 & 6.41 & 8.48 & 1.2 & 4.06 & 19.36 \\
\hline Schizochytrium limacinum & 59.61 & 8.135 & 2.295 & 0.9 & 3.18 & 26.37 \\
\hline Sawdust & 47.4 & 6.2 & 0.2 & 0.1 & 4.7 & 18.83 \\
\hline Straw & 39.3 & 6.2 & 1.4 & 0.7 & 8.5 & 15.80 \\
\hline
\end{tabular}

\subsection{Thermogravimetric analysis}

As it reported that the main decomposition temperatures of Chlorella pyrenoidosa and Schizochytrium limacinum were $294.53^{\circ} \mathrm{C}$ and $428.16^{\circ} \mathrm{C}$, respectively. Which followed by a significant weight loss of $46.7 \%$ and $65.5 \%$ due to that most carbohydrates and proteins had decomposed ${ }^{[16]}$. Another decomposition peak point was found at $642.64^{\circ} \mathrm{C}$ (Chlorella pyrenoidosa) and $760.17^{\circ} \mathrm{C}$ (Schizochytrium limacinum), which can be taken as the complete decomposition temperature of each sample owing to the ash decomposition ${ }^{[17,22-23]}$.

\subsection{Pyrolysis products of sample by GC/MS}

Pyrolyzed products within diverse degradation levels of each sample were obtained by different temperatures. It was suggested that the pyrolyzed products of sample might be pyrolyzed again, and then re-pyrolyzed products could be collected. GC-MS analysis was carried out to determine the percentage of major compounds present in the pyrolysis products derived from the two algae samples, which would provide important references for biomass thermochemical conversion and utilization in industry.

TIC diagram of Chlorella pyrenoidosa obtained at $350^{\circ} \mathrm{C}$ is presented in Figure 1. After further analysis, it can be concluded that the pyrolyzed products of Chlorella pyrenoidosa at $350^{\circ} \mathrm{C}$ mainly contained 161 kinds of substances such as acids, hydrocarbons, alcohols and other organic substances. Therein, the substances whose content was greater than $3 \%$ included 9,12,15-octadecatrienoic acid, (Z,Z,Z)- (34.26\%), bicycle[3.1.1]heptane, 2,6,6-trimethyl- (19.82\%), 3,7,11,15-tetramethyl-2-hexadecen-1-ol (9.79\%), $n$-hexadecanoic acid (5.18\%), 2-hexadecene, 3,7,11,15-tetramethyl-, [R-[R*, $\left.\left.\mathrm{R}^{*}-(\mathrm{E})\right]\right]-(3.85 \%)$ and eicosane, 2-methyl- (3.64\%); the 
retention time were $28.4 \mathrm{~min}, 22.67 \mathrm{~min}, 23.4 \mathrm{~min}, 25.88 \mathrm{~min}$, $22.72 \mathrm{~min}$ and $26.97 \mathrm{~min}$, respectively.

Figure 2 shows the TIC diagrams of Schizochytrium limacinum pyrolytic bio-oil at $350^{\circ} \mathrm{C}$. The pyrolyzed products were primarily made up of 176 kinds of compounds such as hydrocarbons, alcohols, acids and so on. Among which that had more than $3 \%$ consisted of $n$-hexadecanoic acid $(42.87 \%)$, 6-octadecenoic acid (6.61\%), 1,2-benzenediol (6.36\%) and tetradecanoic acid $(5.92 \%)$; the retention times were $25.13 \mathrm{~min}$, $27.44 \mathrm{~min}, 14.17 \mathrm{~min}$ and $21.25 \mathrm{~min}$, respectively.

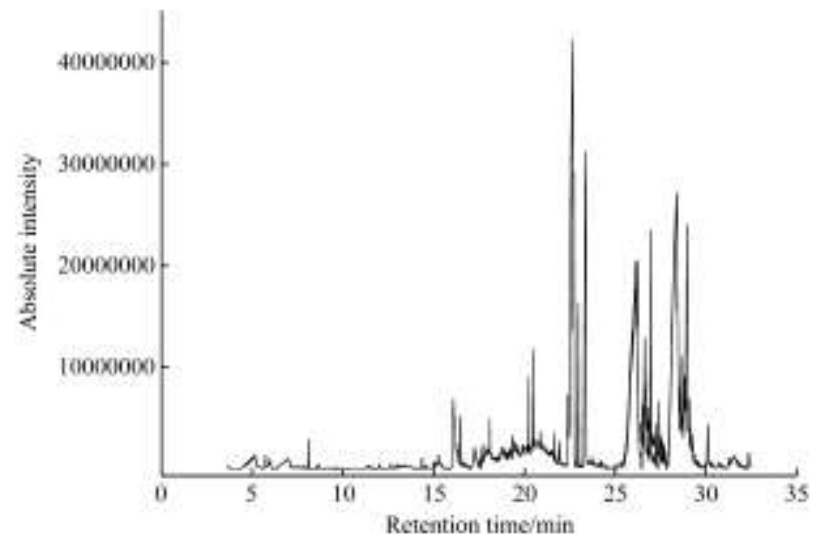

Figure 1 TIC diagram of Chlorella pyrenoidosa pyrolytic bio-oil at $350^{\circ} \mathrm{C}$

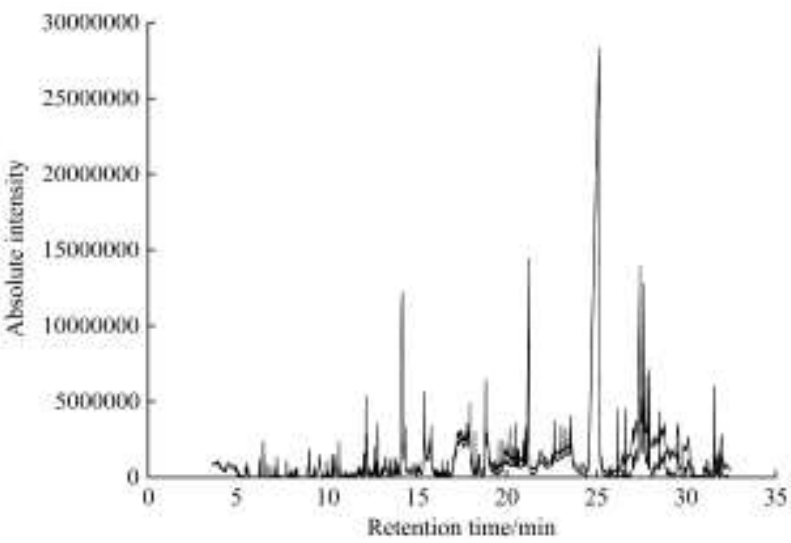

Figure 2 TIC diagram of Schizochytrium limacinum pyrolytic bio-oil at $350^{\circ} \mathrm{C}$

Based on the further analysis of TIC diagrams of each sample, it can also be obtained that the chemical compounds of Chlorella pyrenoidosa identified by GC/MS was the same as those of Schizochytrium limacinum, which could be classified in to several groups such as hydrocarbons, acids, aromatics, nitrogen compounds, phenols and polycyclic aromatic hydrocarbons (PAHs). However, the constituents of each compound were not the same at all. In order to better study the influences on pyrolyzed products by temperature, the substances that the match quality were over $80 \%$ in each sample under each temperature shall be classified and summarized according to chemical compounds ${ }^{[1,3-4]}$.

Hydrocarbons that naturally present in fossil fuel, are valuable organic components in bio-oil for fuel application ${ }^{[21,24]}$. Among the compounds listed in Tables 3, the relative content of hydrocarbons in Chlorella pyrenoidosa firstly decreased from $350^{\circ} \mathrm{C}$ to $450^{\circ} \mathrm{C}$, then up to the highest content of $6.51 \%$ at $550^{\circ} \mathrm{C}$, and finally decreased to $0.05 \%$ with increasing temperature from $550^{\circ} \mathrm{C}$ to $750^{\circ} \mathrm{C}$. Long-chain fatty acids could not only generate biodiesel, but also produce straight-chain hydrocarbons via the denitrification and deoxygenation reactions ${ }^{[3]}$. Only three kinds of

fatty acids were detected and identified as long-chain compounds $\left(\mathrm{C}_{16}-\mathrm{C}_{18}\right)$ that were suitable for biodiesel production ${ }^{[18]}$. The relative content of fatty acids decreased with the increasing temperature in the range of $350^{\circ} \mathrm{C}$ to $750^{\circ} \mathrm{C}$ and the highest content $\left(39.44 \%\right.$ ) was obtained at $350^{\circ} \mathrm{C}$. As important fuel additives, aromatics could increase octane number of transportation fuel ${ }^{[22]}$. The aromatics listed in Table 3 were consisted of benzene and its derivatives, and of which was not detected until $450^{\circ} \mathrm{C}$, the relative content of aromatics increased from $450^{\circ} \mathrm{C}$ to $650^{\circ} \mathrm{C}$ and reached up to the highest content of $28.24 \%$ at $650^{\circ} \mathrm{C}$, then followed by a little decrease with increasing temperature from $650^{\circ} \mathrm{C}$ to $750^{\circ} \mathrm{C}$.

Table 3 Effects of temperature on identification and quantification of chemical compounds from Chlorella pyrenoidosapyrolyzed at $350^{\circ} \mathrm{C}-750^{\circ} \mathrm{C}\left(Q^{2}\right.$ ality $\left.>80 \%\right)$

\begin{tabular}{|c|c|c|c|c|c|}
\hline \multirow{2}{*}{ Compounds } & \multicolumn{5}{|c|}{ Relative content $/ \%$} \\
\hline & $350^{\circ} \mathrm{C}$ & $450^{\circ} \mathrm{C}$ & $550^{\circ} \mathrm{C}$ & $650^{\circ} \mathrm{C}$ & $750^{\circ} \mathrm{C}$ \\
\hline \multicolumn{6}{|l|}{ Hydrocarbons } \\
\hline Tricyclo[4.3.1.0(2,5)]decane & - & - & 1.19 & - & - \\
\hline Tridecane & - & 0.52 & - & - & - \\
\hline Nonadecane & 1.03 & - & - & - & - \\
\hline Bicyclo[4.2.0]octa-1,3,5-triene & - & - & - & 4.78 & - \\
\hline 1,3,5,7-Cyclooctatetraene & - & - & 2.02 & - & 0.05 \\
\hline $\begin{array}{l}\text { 2-Hexadecene, 3,7,11,15-tetramethyl-, } \\
{\left[\mathrm{R}-\left[\mathrm{R}^{*}, \mathrm{R}^{*} \text {-(E)]]- }\right.\right.}\end{array}$ & 3.85 & 2.81 & 3.30 & - & - \\
\hline Sum & 4.88 & 3.33 & 6.51 & 4.78 & 0.05 \\
\hline \multicolumn{6}{|l|}{ Fatty acids } \\
\hline n-Hexadecanoic acid & 5.18 & 6.49 & 2.24 & 0.89 & 2.22 \\
\hline 9,12-Octadecadienoic acid (Z,Z)- & - & 0.22 & - & - & - \\
\hline 9,12,15-Octadecatrienoic acid, (Z,Z,Z)- & 34.26 & 9.48 & - & - & - \\
\hline Sum & 39.44 & 16.19 & 2.24 & 0.89 & 2.22 \\
\hline \multicolumn{6}{|l|}{ Aromatics } \\
\hline Benzene, 1-propynyl- & - & - & - & - & 2.04 \\
\hline Benzene, 1-ethyl-2-methyl- & - & - & - & - & 0.30 \\
\hline Benzene, 1-ethyl-4-methyl- & - & - & - & - & 0.25 \\
\hline Benzene, 1,3,5-trimethyl- & - & - & - & - & 0.33 \\
\hline Toluene & - & - & 17.07 & 24.72 & 18.59 \\
\hline Ethylbenzene & - & 0.78 & 4.56 & 3.62 & 4.02 \\
\hline Sum & 0 & 0.78 & 21.63 & 28.24 & 25.33 \\
\hline \multicolumn{6}{|l|}{ Nitrogen compounds } \\
\hline Hexadecanamide & 1.03 & 0.25 & - & - & 0.96 \\
\hline Benzyl nitrile & - & 0.99 & - & 0.07 & - \\
\hline Indole & 1.68 & 2.86 & 6.66 & - & 7.35 \\
\hline Aniline & - & - & - & 0.29 & - \\
\hline Pyridine, 2-methyl- & - & - & - & - & 0.99 \\
\hline Sum & 2.71 & 4.10 & 6.66 & 0.36 & 9.30 \\
\hline \multicolumn{6}{|l|}{ Phenols } \\
\hline Phenol & - & 3.24 & 2.38 & 4.30 & 1.98 \\
\hline Phenol, 4-methyl- & - & - & 5.76 & 7.02 & 5.64 \\
\hline Sum & 0 & 3.24 & 8.14 & 11.32 & 7.62 \\
\hline \multicolumn{6}{|l|}{ PAHs } \\
\hline Naphthalene, 1-methyl- & - & - & - & - & 1.14 \\
\hline Naphthalene, 1,4-dimethyl- & - & - & - & - & 0.39 \\
\hline Naphthalene, 1,5-dimethyl- & - & - & - & 0.44 & - \\
\hline Sum & 0 & 0 & 0 & 0.44 & 1.53 \\
\hline
\end{tabular}


Besides, nitrogen compounds were mainly comprised of amides, nitriles, indoles and pyridines, which account for potential emission of nitrogen oxides during fuel combustion ${ }^{[19-21]}$. The content of nitrogen compounds increased with increasing temperature from $350^{\circ} \mathrm{C}$ to $550^{\circ} \mathrm{C}$, then had a huge decline in the range of $550^{\circ} \mathrm{C}$ to $650^{\circ} \mathrm{C}$, and finally reached the maximum content of $9.3 \%$ at $750^{\circ} \mathrm{C}$.

A few typical pollutants called PAHs which naturally exist in fossil fuels were also detected. The relative content of PAHs was not detected until the temperature reached $650^{\circ} \mathrm{C}$, which was only $0.44 \%$. Then with the increased temperature the highest content of $1.53 \%$ was shown at $750^{\circ} \mathrm{C}$. Furthermore, the relative content of phenols and its derivatives, which are of commercial importance, increased with the rising temperature in the range of $350^{\circ} \mathrm{C}$ to $650^{\circ} \mathrm{C}$, and reached the highest content of $11.32 \%$ at $650^{\circ} \mathrm{C}$.

As for Schizochytrium limacinum, different hydrocarbon compounds were released at different temperatures as the temperature increased (Table 4). The hydrocarbons of pyrolysis products from Schizochytrium limacinum were mainly consisted of alkanes and alkenes, which had a steady increase with the elevated temperature from $350^{\circ} \mathrm{C}$ to $650^{\circ} \mathrm{C}$. The highest content of $17.58 \%$ was obtained at $650^{\circ} \mathrm{C}$, which was much higher than Chlorella pyrenoidosa $(6.51 \%)$. Table 4 further shows that the trend of fatty acids content showed a gradual descending trend accompanied by an increase in temperature from $350^{\circ} \mathrm{C}$ to $750^{\circ} \mathrm{C}$, which was in accordance with Chlorella pyrenoidosa. The relative content of fatty acids from Schizochytrium limacinum reached its highest value $(59.73 \%)$ at $350^{\circ} \mathrm{C}$, and was also higher than Chlorella pyrenoidosa (39.44\%) due to its high lipid content which was mainly converted to fatty acids during pyrolysis process $^{[21]}$. Both results (Chlorella pyrenoidosa and Schizochytrium limacinum) were in accordance with previous reports that lower temperature could generate more fatty acids during the pyrolysis process ${ }^{[21,22]}$. However, the relative content of aromatics for Schizochytrium limacinum showed a step increase with the elevated temperature from $350^{\circ} \mathrm{C}$ to $750^{\circ} \mathrm{C}$, especially in the range of $650^{\circ} \mathrm{C}$ to $750^{\circ} \mathrm{C}$, the aromatics content had a huge generation and climbed up to the highest value of $33.27 \%$ at $750^{\circ} \mathrm{C}$ which was much higher than Chlorella pyrenoidosa $(28.24 \%)$.

The relative content of nitrogen compounds increased with increasing temperature from $350^{\circ} \mathrm{C}$ to $650^{\circ} \mathrm{C}$ and up to its highest value of $3.94 \%$, which was lower than Chlorella pyrenoidosa (9.30\%), this was probably due to the $\mathrm{N}$ content of Schizochytrium limacinum was much lower than that of Chlorella pyrenoidosa ${ }^{[19,23]}$. The relative content of PAHs showed a step increase with elevated temperature in the range of $350^{\circ} \mathrm{C}$ to $650^{\circ} \mathrm{C}$; when the temperature raised up to $750^{\circ} \mathrm{C}$, the PAHs content had a huge boost and reached its highest value of $6.52 \%$ which was also higher than Chlorella pyrenoidosa (1.53\%). Besides, a few phenols compounds were detected and decreased with elevated temperature from $350^{\circ} \mathrm{C}$ to $750^{\circ} \mathrm{C}$, and the highest content $(6.66 \%)$ obtained at $350^{\circ} \mathrm{C}$ was lower than Chlorella pyrenoidosa (11.32\%).

In order to perform a better comparison of the bio-oil production potential with these two microalage strains, Figure 3 showed the sum of relative content of hydrocarbons, aromatics and acids for Chlorella pyrenoidosa and Schizochytrium limacinum as a function of temperature. As seen, the sum of relative content of the three substances achieved maximum of $44.32 \%$ and $60.99 \%$ at $350^{\circ} \mathrm{C}$ respectively. Pollutants release of nitrogen compounds

were respectively $2.71 \%$ (Chlorella pyrenoidosa) and $0.7 \%$ (Schizochytrium limacinum) at the same time, while pollutants release of PAHs were not detected. It was clear that the pyrolysis products obtained from Schizochytrium limacinum had higher relative content of the three substances and lower pollutants than Chlorella pyrenoidosa, which suggested that Schizochytrium limacinum was more suitable for the exploitation of energy through pyrolytic conversion.

Table 4 Effects of temperature on identification and quantification of chemical compounds from Schizochytrium limacinumpyrolyzed at $350^{\circ} \mathrm{C}-750^{\circ} \mathrm{C}$ (Quality > 80\%)

\begin{tabular}{|c|c|c|c|c|c|}
\hline \multirow{2}{*}{ Compounds } & \multicolumn{5}{|c|}{ Peak area/\% } \\
\hline & $350^{\circ} \mathrm{C}$ & $450^{\circ} \mathrm{C}$ & $550^{\circ} \mathrm{C}$ & $650^{\circ} \mathrm{C}$ & $750^{\circ} \mathrm{C}$ \\
\hline \multicolumn{6}{|l|}{ Hydrocarbons } \\
\hline Cyclopropane, 1-methyl-2-pentyl- & - & - & 2.67 & 5.27 & 1.83 \\
\hline Cyclopropane, 1-pentyl-2-propyl- & - & - & - & 3.05 & - \\
\hline cis-1-Butyl-2-methylcyclopropane & - & - & 2.00 & - & 1.85 \\
\hline Cyclododecane & - & - & 3.27 & - & 5.82 \\
\hline Tridecane & 0.01 & - & 0.72 & 0.38 & 0.37 \\
\hline Tetradecane & - & 1.86 & 0.33 & 3.23 & - \\
\hline Pentadecane & 1.25 & 5.75 & 4.75 & - & 1.46 \\
\hline 1-Heptene & - & - & 0.58 & 2.51 & - \\
\hline 1,3,5-Cycloheptatriene & - & 1.36 & - & - & 0.31 \\
\hline 1-Decene & - & - & 3.80 & 5.89 & 2.67 \\
\hline 1-Undecene & - & - & 1.18 & - & 2.51 \\
\hline 1-Dodecene & - & - & 1.50 & 3.57 & - \\
\hline 1-Tridecene & - & - & 0.86 & 2.00 & 1.94 \\
\hline Sum & 1.26 & 7.97 & 13.72 & 17.58 & 9.26 \\
\hline \multicolumn{6}{|l|}{ Fatty acids } \\
\hline Dodecanoic acid & 1.74 & 0.2 & - & - & - \\
\hline Tetradecanoic acid & 5.92 & 9.48 & 7.87 & - & 1.64 \\
\hline n-Hexadecanoic acid & 42.87 & 33.83 & 18.97 & 2.18 & 1.07 \\
\hline Heptadecanoic acid & 0.09 & - & - & - & - \\
\hline Octadecanoic acid & 2.5 & 2.22 & - & - & - \\
\hline 6-Octadecenoic acid & 6.61 & - & - & - & - \\
\hline 9,12-Octadecadienoic acid (Z,Z)- & - & 0.78 & - & - & - \\
\hline Sum & 59.73 & 46.51 & 26.84 & 2.18 & 2.71 \\
\hline \multicolumn{6}{|l|}{ Aromatics } \\
\hline Benzene, propyl- & - & 0.28 & 1.31 & 1.24 & 1.19 \\
\hline Benzene, butyl- & - & 0.41 & 0.36 & - & - \\
\hline Benzene, 1-butynyl- & - & - & - & 1.57 & 4.75 \\
\hline Benzene, 1,3-dimethyl- & - & - & - & - & 1.91 \\
\hline Benzene, 1-ethenyl-2-methyl- & - & - & - & - & 2.41 \\
\hline Benzene, 1-ethyl-2-methyl- & - & - & - & - & 1.75 \\
\hline Benzene, 1-ethyl-3-methyl- & - & - & - & 1.08 & 0.04 \\
\hline Biphenyl & - & - & - & 0.29 & 0.62 \\
\hline Toluene & - & - & 1.86 & 7.94 & 9.85 \\
\hline p-Xylene & - & 0.74 & - & 1.26 & - \\
\hline Ethylbenzene & - & - & - & 2.67 & 3.44 \\
\hline Styrene & - & 0.03 & - & 4.32 & 6.87 \\
\hline cis-.beta.-Methylstyrene & - & - & - & 1.23 & 0.44 \\
\hline Sum & 0 & 1.46 & 3.53 & 22.60 & 33.27 \\
\hline
\end{tabular}




\begin{tabular}{|c|c|c|c|c|c|}
\hline \multirow{2}{*}{ Compounds } & \multicolumn{5}{|c|}{ Peak area $/ \%$} \\
\hline & $350^{\circ} \mathrm{C}$ & $450^{\circ} \mathrm{C}$ & $550^{\circ} \mathrm{C}$ & $650^{\circ} \mathrm{C}$ & $750^{\circ} \mathrm{C}$ \\
\hline \multicolumn{6}{|l|}{ Nitrogen compounds } \\
\hline Tetradecanamide & - & - & - & 1.27 & 0.66 \\
\hline Hexadecanamide & 0.70 & 0.20 & 1.27 & 2.18 & 2.09 \\
\hline Hexadecanenitrile & - & - & 0.55 & 0.46 & - \\
\hline Indole & - & 0.24 & - & - & - \\
\hline Pyridine & - & 0.19 & - & 0.03 & - \\
\hline Sum & 0.70 & 0.63 & 1.82 & 3.94 & 2.74 \\
\hline \multicolumn{6}{|l|}{ Phenols } \\
\hline $\begin{array}{l}\text { Phenol, 4,6-di(1,1-dimethylethyl)- } \\
\text { 2-methyl- }\end{array}$ & 0.3 & - & - & - & - \\
\hline 1,2-Benzenediol & 6.36 & 1.39 & 0.05 & - & - \\
\hline Sum & 6.66 & 1.39 & 0.05 & 0 & 0 \\
\hline \multicolumn{6}{|l|}{ PAHs } \\
\hline Naphthalene & - & - & - & 0.10 & 0.03 \\
\hline Naphthalene, 1-methyl- & - & 0.06 & - & 0.59 & 2.06 \\
\hline Naphthalene, 2-ethenyl- & - & - & - & - & 0.74 \\
\hline Naphthalene, 1,3-dimethyl- & - & - & - & - & 0.57 \\
\hline Naphthalene, 1,2-dihydro- & - & - & 0.55 & - & 2.1 \\
\hline $\begin{array}{l}\text { 1,4-Methanonaphthalene, } \\
\text { 1,4-dihydro- }\end{array}$ & - & 0.07 & - & 0.02 & 1.02 \\
\hline Sum & 0 & 0.13 & 0.55 & 0.71 & 6.52 \\
\hline
\end{tabular}

The Research Foundation for Youth Scholars of Beijing Technology and Business University (PXM2018_014213_000033).

\section{[References]}

[1] Li G, Ji F, Xiang S, Zhou Y G, Jiang M M, Huang Z G. Analytical study on pyrolyzed products of Desmodesmus sp. cultivated in BG11. Int $\mathbf{J}$ Agric \& Biol Eng, 2017; 10(3): 218-226.

[2] Kebelmann K, Hornung A, Karsten U, Griffiths, G. Intermediate pyrolysis and product identification by TGA and Py-GC/MS of green microalgae and their extracted protein and lipid components. Biomass \& Bioenergy, 2013; 49: 38-48.

[3] Li G, Dong R J, Fu N, Zhou Y G, Li D, Chen X D. Characterization of pyrolysis products obtained from Desmodesmus sp. cultivated in anaerobic digested effluents (DADE). International Journal of Food Engineering, 2015; 11(6): 825-832.

[4] Li G, Xiang S N, Ji F, Zhou Y G, Huang Z G. Thermal cracking products and bio-oil production from microalgae Desmodesmus sp. Int $\mathrm{J}$ Agric \& Biol Eng, 2017; 10(4): 198-206..

[5] Brennan L, Owende P. Biofuels from microalgae-a review of technologies for production, processing, and extractions of biofuels and co-products. Renewable and Sustainable Energy Reviews, 2010; 14(2): 557-577.

[6] Miao X, Wu Q, Yang C. Fast pyrolysis of microalgae to produce renewable fuels. Journal of Analytical and Applied Pyrolysis, 2004; 71: 855-863.

[7] Miao X, Wu Q. High yield bio-oil production from fast pyrolysis by metabolic controlling of Chlorella protothecoides. Journal of Biotechnology, 2004; 110: 85-93.

[8] Demirbaş A. Biomass resource facilities and biomass conversion processing for fuels and chemicals. Energy Conversion and Management, 2001; 42: 1357-1378.

[9] Li X H, Meng Y Z, Zhu Q, Tjong S C. Thermal decomposition characteristics of poly (propylene carbonate) using TG/IR and Py-GC/MS techniques. Polymer Degradation and Stability, 2003; 81: 157-165.

[10] Ralph J, Hatfield R D. Pyrolysis-GC-MS characterization of forage materials. Journal of Agricultural and Food Chemistry, 1991; 39: 1426-1437.

[11] Ross A B, Anastasakis K, Kubacki M, Jones J M. Investigation of the pyrolysis behaviour of brown algae before and after pre-treatment using PY-GC/MS and TGA. Journal of Analytical and Applied Pyrolysis, 2009; 85: 3-10.

[12] Scholze B, Meier D. Characterization of the water-insoluble fraction from pyrolysis oil (pyrolytic lignin). Part I. PY-GC/MS, FTIR, and functional groups. Journal of Immunology, 2001; 60: 41-54.

[13] Mahinpey N, Murugan P, Mani T, Raina R. Analysis of bio-oil, biogas, and biochar from pressurized pyrolysis of wheat straw using a tubular reactor. Energy and Fuels; 2009, 23: 2736-2742.

Figure 3 Sum of relative percentages of hydrocarbons, aromatics and acids under different pyrolysis temperatures $\left(350^{\circ} \mathrm{C}-750^{\circ} \mathrm{C}\right)$

\section{Conclusions}

The main categories of pyrolysis products of Chlorella pyrenoidosa were hydrocarbons, aromatics, fatty acids, nitrogen compounds, PAHs, phenols and so on, which were the same as that of Schizochytrium limacinum. The pyrolysis of Chlorella pyrenoidosa at $350^{\circ} \mathrm{C}$ produced a maximum yield of bio-oil (44.32\%) compared to $60.99 \%$ that Schizochytrium limacinum generated at $350^{\circ} \mathrm{C}$; furthermore, the generation of such pollutants (nitrogen compounds) during Chlorella pyrenoidosa pyrolysis at $350^{\circ} \mathrm{C}$ was $2.71 \%$ which was much higher than that of Schizochytrium limacinum $(0.7 \%)$ at $350^{\circ} \mathrm{C}$. Hence, Schizochytrium limacinum is more suitable for producing bio-oil in terms of optimal quality and yield against Chlorella pyrenoidosa.

\section{Acknowledgment}

This research was supported by The Beijing Municipal Education Commission General Project (KM201810011002), and

[14] TA Instruments. Simultaneous DSC-TGA Getting Started Guide. TA Instruments-Waters LLC, 109 Lukens Drive, New Castle, DE 19720, USA, 2004.

[15] Lazdovica K, Kampars V, Liepina L, Vilka M. Comparative study on thermal pyrolysis of buckwheat and wheat straws by using TGA-FTIR and Py-GC/MS methods. Journal of Analytical and Applied Pyrolysis, 2017; 124: $1-15$.

[16] Ross A B, Jones J M, Kubacki M L, Brideman T. Classification of macroalgae as fuel and its thermochemical behavior. Bioresource Technology, 2008; 99: 6494-6504.

[17] Bae Y J, Ryu C, Jeon J K, Park J, Suh D J, Suh Y W. The characteristics of bio-oil produced from the pyrolysis of three marine macroalgae. Bioresource Technology, 2011; 102: 3512-3520.

[18] Wang L, Li Y, Chen P, Min M, Chen Y, Zhu J, et al. Anaerobic digested dairy manure as a nutrient supplement for cultivation of oil-rich green microalgae Chlorella sp. Bioresource Technology, 2010; 101(8): 2623-2628.

[19] Maddi B, Viamajala S, Varanasi S. Comparative study of pyrolysis of algal biomass from natural lake blooms with lignocellulosic biomass. Bioresource Technology, 2011; 102: 11018-11026.

[20] Thangalazhy-Gopakumar S, Adhikari S, Chattanathan S A, Gupta R B. Catalytic pyrolysis of green algae for hydrocarbon production using $\mathrm{H}^{+}$ZSM-5 catalyst. Bioresource Technology, 2012; 118: 150-157. 
[21] Li R, Zhong Z, Jin B, Zheng A. Selection of temperature for bio-oil production from pyrolysis of algae from lake blooms. Energy and Fuel, 2012; 26: 2996-3002.

[22] Li G, Zhou Y G, Fang J, Liu Y, Adhikari B, Li T, et al. Yield and characteristics of pyrolysis products obtained from Schizochytrium limacinum under different temperature regimes. Energies, 2013; 6(7): 3339-3352.
[23] Li G, Dong $\mathrm{R}$ J, Fu N, Zhou Y G, Li D, Chen X D, et al. Temperature-oriented pyrolysis on the decomposition characteristics of Chlorella pyrenoidosa. International Journal of Food Engineering, 2016; 12(3): 295-301.

[24] Thangalazhy-Gopakumar S, Adhikari S, Gupta R B. Catalytic pyrolysis of biomass over $\mathrm{H}^{+} \mathrm{ZSM}-5$ under hydrogen pressure. Energy and Fuels, 2012; 26: 5300-5306. 